\title{
Long-term prescribing of new oral anticoagulants
}

\section{Paul KL Chin \\ Research fellow}

\section{Matthew P Doogue}

Associate professor Department of Medicine

University of Otago

Christchurch

New Zealand

\section{Keywords}

anticoagulant, apixaban, atrial fibrillation, bleeding, dabigatran, rivaroxaban, stroke, thromboembolism, warfarin

Aust Prescr 2016;39:200-4 http://dx.doi.org/10.18773/ austprescr.2016.068

Corrected 20 February 2017

This is the corrected version of the article.

Correction notice available at:

http://dx.doi.org/10.18773/ austprescr.2017.025

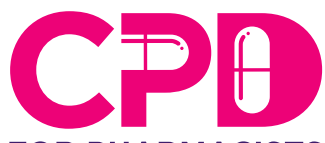

FOR PHARMACISTS

This article has a continuing professional development activity for pharmacists available at http://learn.nps.org.au

\section{SUMMARY}

Warfarin and the new oral anticoagulants are licensed for non-valvular atrial fibrillation and venous thromboembolism.

The choice of anticoagulant depends on the characteristics of the patient and the medicine. Key considerations include patient adherence, kidney and liver function, and potential interactions with concomitant drugs. Dosing should accommodate these factors.

Patients should be regularly monitored for bleeding, adherence to treatment, and changing comorbidities and concomitant drugs. Renal function should be checked at least annually.

Other than idarucizumab for dabigatran, there are no widely available antidotes for the new oral anticoagulants. In a patient with normal renal and hepatic function, drug concentrations and anticoagulant effect are expected to diminish by over $90 \%$ after stopping treatment for 48 hours.

\section{Introduction}

Three new oral anticoagulants (NOACs) - dabigatran, rivaroxaban and apixaban - were listed on the Pharmaceutical Benefits Scheme in 2012. These drugs are also known as non-vitamin $\mathrm{K}$ antagonists and are alternatives to warfarin for some longterm indications, including the prevention of thromboembolism in non-valvular atrial fibrillation and the treatment of venous thromboembolism (see Table). ${ }^{1,2}$

A key difference between NOACs and warfarin is in the use of coagulation testing. Warfarin dosing is guided by a coagulation test, the INR. With NOACs, coagulation monitoring was not used in the major randomised controlled trials that support their use. Once the decision to anticoagulate has been made, the following questions need to be considered:

- Which anticoagulant drug should be prescribed?

- What dose should be used?

- What monitoring do patients need?

- How is bleeding managed if it occurs?

\section{Choice of oral anticoagulant}

All the major trials comparing NOACs to warfarin have been non-inferiority studies. ${ }^{3}$ These trials were not designed to test superiority over warfarin in relation to thrombosis and bleeding, which is an important limitation of such claims based on the data. The trials found the newer drugs were non-inferior to warfarin for the primary outcomes (including thrombosis and bleeding) when used to treat atrial fibrillation and venous thromboembolism.
Matching the characteristics of the individual patient to the characteristics of each oral anticoagulant is important when choosing therapy. ${ }^{4}$ The Table lists approved indications and key characteristics of oral anticoagulants. A major difference between NOACs is the contribution of the kidneys to drug clearance, which is greatest for dabigatran. Key decision points when choosing an oral anticoagulant are illustrated in the Figure.

\section{Patient characteristics}

Warfarin should be used for patients with mechanical heart valves as data for the NOACs are either lacking or show inferiority to warfarin. We recommend that patients established on warfarin with a high percentage of time in the therapeutic range (e.g. $>70 \%$ of INR values at target) ${ }^{5}$ should remain on warfarin.

The uncertainty around dosing of NOACs in severe liver impairment (e.g. Child Pugh C) or renal impairment (e.g. creatinine clearance $<30 \mathrm{~mL} / \mathrm{min}$ ) means that warfarin is favoured in these patients. NOACs are not recommended during pregnancy or breastfeeding as there are alternatives associated with greater safety and efficacy data. Warfarin is teratogenic and thus contraindicated during pregnancy, but is compatible with breastfeeding as transfer into breastmilk is negligible.

\section{Drug-drug interactions}

Co-administration of medicines that are strong enzyme or transporter inducers (e.g. rifampicin) or inhibitors (e.g. erythromycin) ${ }^{6}$ are expected to 


\section{Table Characteristics of oral anticoagulants}

\begin{tabular}{|c|c|c|c|c|}
\hline & Warfarin & Apixaban & Dabigatran & Rivaroxaban \\
\hline Brand & Coumadin, Marevan & Eliquis & Pradaxa & Xarelto \\
\hline Licensed indications & $\begin{array}{l}\text { AF, VTE, valvular } \\
\text { heart disease }\end{array}$ & AF, VTE & AF & AF, VTE \\
\hline Dosing frequency & daily & twice daily & twice daily & daily $^{\dagger}$ \\
\hline Oral bioavailability $\ddagger$ & $100 \%$ & $50 \%$ & $7 \%$ & $>80 \% \S$ \\
\hline Excretion unchanged in urine $\ddagger$ & $0 \%$ & $34 \%$ & $80 \%$ & $36 \%$ \\
\hline Major metabolic/transport pathways & CYP2C9 & CYP3A4, P-glycoprotein & P-glycoprotein \# & CYP3A4, P-glycoprotein \\
\hline \multicolumn{5}{|l|}{ Drug half-life 9} \\
\hline healthy young individuals & 40 hours & 10 hours & 14 hours & 7 hours \\
\hline \multicolumn{5}{|l|}{ chronic kidney disease } \\
\hline moderate & not reported & not reported & 19 hours & 9 hours \\
\hline severe & - & - & 28 hours & 10 hours \\
\hline \multicolumn{5}{|l|}{ chronic liver disease } \\
\hline moderate & not reported & not reported & 12 hours & 10 hours \\
\hline severe & - & - & not reported & not reported \\
\hline \multicolumn{5}{|l|}{$\begin{array}{l}\text { Effect of chronic disease on } \\
\text { anticoagulant concentrations ** } \\
\text { chronic kidney disease }\end{array}$} \\
\hline moderate & not reported & $30 \%$ increase & $210 \%$ increase & $50 \%$ increase \\
\hline severe & - & $40 \%$ increase & $530 \%$ increase & $60 \%$ increase \\
\hline \multicolumn{5}{|l|}{ chronic liver disease } \\
\hline moderate & not reported & $9 \%$ increase & $6 \%$ decrease & $120 \%$ increase \\
\hline severe & - & not reported & not reported & not reported \\
\hline \multirow[t]{2}{*}{$\begin{array}{l}\text { Effect of concomitant drugs on } \\
\text { anticoagulant concentrations }{ }^{\dagger \dagger}\end{array}$} & $\begin{array}{l}\text { Amiodarone increases } \\
\text { anticoagulant }\end{array}$ & $\begin{array}{l}\text { Erythromycin increases } \\
\text { anticoagulant }\end{array}$ & $\begin{array}{l}\text { Verapamil increases } \\
\text { anticoagulant }\end{array}$ & $\begin{array}{l}\text { Erythromycin increases } \\
\text { anticoagulant }\end{array}$ \\
\hline & $\begin{array}{l}\text { Rifampicin decreases } \\
\text { anticoagulant }\end{array}$ & $\begin{array}{l}\text { Rifampicin decreases } \\
\text { anticoagulant }\end{array}$ & $\begin{array}{l}\text { Rifampicin decreases } \\
\text { anticoagulant }\end{array}$ & $\begin{array}{l}\text { Rifampicin decreases } \\
\text { anticoagulant }\end{array}$ \\
\hline
\end{tabular}

AF atrial fibrillation VTE venous thromboembolism CYP cytochrome P450

All values are means.

+ Initial dosing in normal renal function is twice daily, maintenance dose is once daily.

$\ddagger$ Values in healthy young individuals.

$\S$ When administered with food (when fasting, the oral bioavailability of rivaroxaban $20 \mathrm{mg}$ is 66\%).

\# Dabigatran etexilate, the prodrug of dabigatran, but not dabigatran itself, is a P-glycoprotein substrate.

- Kidney and liver disease usually reduce drug clearance and thus increase drug half-lives.

** For example, $100 \%$ increase indicates that concentrations were double that of the reference healthy group.

+† See Australian Medicines Handbook interaction tables for more examples of drugs that inhibit or induce metabolic or transport pathways (https://amhonline.amh.net.au/interactions).

Source: References 1, 2

cause significant changes in oral anticoagulant drug concentrations, with corresponding changes in anticoagulation effect (Table).' While drug interactions with warfarin can be managed by dose adjustment and INR monitoring, it is less clear how to proceed with dabigatran, rivaroxaban and apixaban. We recommend avoiding concomitant strong inhibitors and inducers of cytochrome P450 (CYP) 3A4 and P-glycoprotein with NOACs. The Table lists some examples of interacting drugs, with more comprehensive lists available in the Australian Medicines Handbook. 


\section{Fig. Choosing an oral anticoagulant for long-term use}

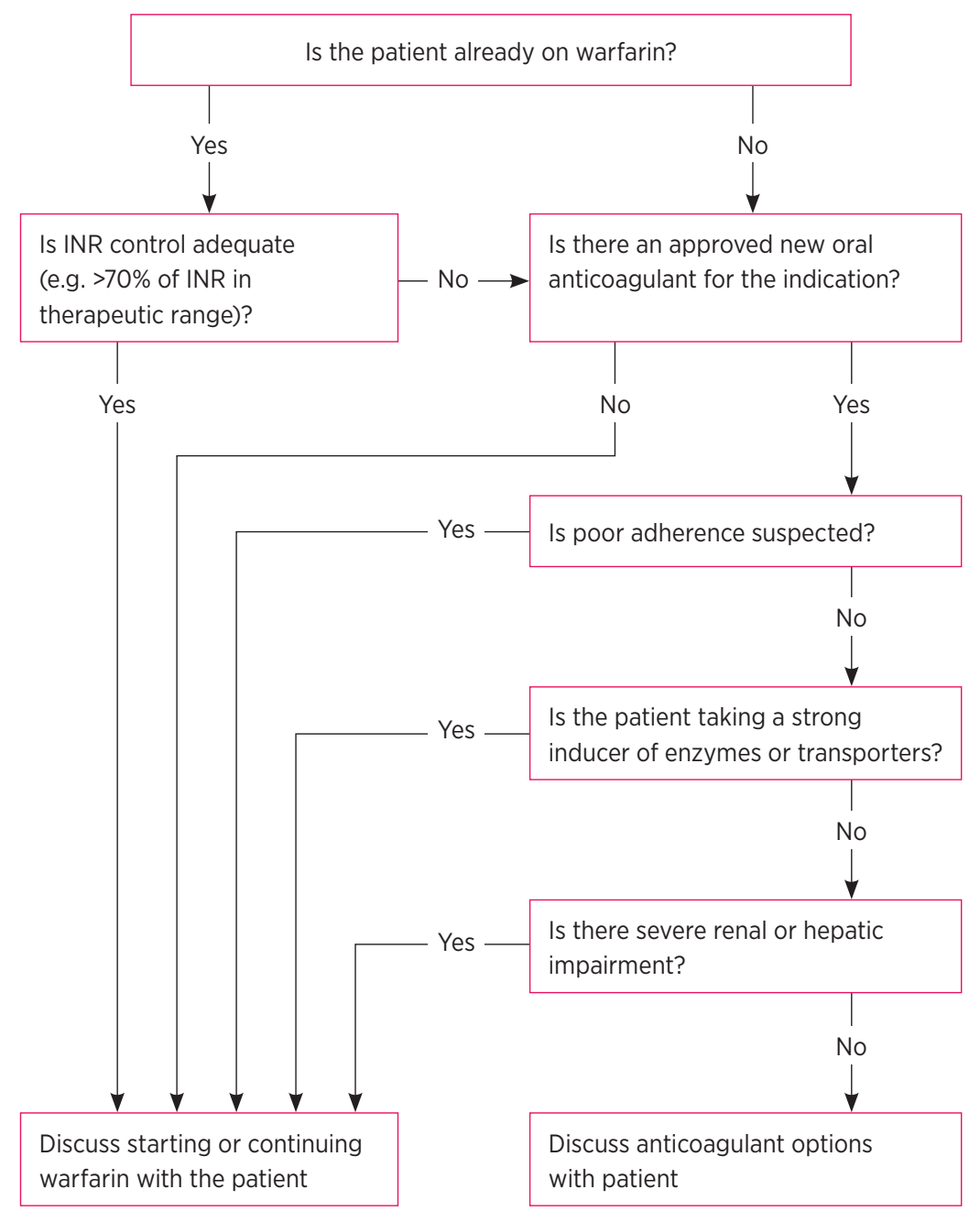

\section{Patient preference}

After drug and patient characteristics have been considered, patient preferences and the prescriber's experience with different anticoagulants should be considered. For example, some patients prefer to avoid frequent blood tests. Conversely other patients taking warfarin view INR monitoring as a benefit rather than a barrier to therapy, and gain reassurance from these tests. ${ }^{7}$ There should still be regular blood tests for renal function, given that all NOACs are subject to some degree of renal elimination. Finally, as NOACs have shorter half-lives than warfarin (Table), warfarin may be preferred if daily adherence is a problem. Patients will have a lower clinical risk of thrombosis if they forget to take warfarin than if they forget to take one of the NOACs. Apixaban and rivaroxaban may be kept in dosette boxes. In contrast, dabigatran should be kept in its foil blister pack or bottle to minimise the risk of degradation.

\section{Dose}

Pharmacokinetic and pharmacodynamic factors should be considered when selecting doses of the NOACs. Pharmacokinetic factors affecting drug concentrations are outlined in the Table, and include renal and hepatic impairment and concomitant interacting medicines that affect drug metabolism (e.g. CYP3A4) or P-glycoprotein. Pharmacodynamic factors affect the risk of thromboembolism or bleeding independently of any effect on drug concentrations. There is overlap between factors that raise thromboembolic risk (age over 65 years, hypertension, known vascular disease such as previous stroke or myocardial infarction, heart failure, diabetes, female gender) and bleeding risk (age over 65 years, uncontrolled hypertension, previous stroke, abnormal renal and liver function, bleeding history, excess alcohol and concomitant medicines such as antiplatelet drugs, non-steroidal anti-inflammatory drugs and selective serotonin reuptake inhibitors). ${ }^{8,9}$

Dosing guidance in the product information is a good starting point to select the dose. However, some of the information is inconsistent or unclear, especially for pharmacokinetic drug interactions.

When considering the risk of bleeding, for patients with one pharmacokinetic factor such as moderate renal impairment, doses can be adjusted in proportion to the predicted changes in anticoagulant concentrations outlined in the Table. This was not done in the trials of apixaban, dabigatran and rivaroxaban, but the principles of dose-individualisation are well established across many drugs. There is evidence that dose adjustment of dabigatran beyond what was described in the trial protocol for atrial fibrillation is associated with improved clinical outcomes. ${ }^{10}$ Dosing patients with several coexisting factors is difficult without a reliable method of monitoring the drug's anticoagulant effect.

\section{Clinical and laboratory monitoring}

Clinical monitoring begins with monitoring patient events and educating the patient to report bleeding. Poor adherence is the most common cause of treatment failure so adherence should be

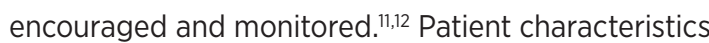
such as comorbidities and concomitant medications can change. This may alter the risks of thrombosis and bleeding so dose adjustment or a change in treatment may need to be considered. As a minimum, these components of clinical monitoring should occur with every prescription of an oral anticoagulant (see Box). 


\section{Renal function}

Renal function should be monitored regularly because renal impairment increases the risk of bleeding with all of the NOACs. ${ }^{12,13}$ We suggest 6-12 monthly monitoring, and additional testing with changing clinical circumstances, such as a change in diuretics in patients with heart failure. It is important to note that all of the oral anticoagulant trials used the CockcroftGault estimation of creatinine clearance to gauge renal function (in $\mathrm{mL} / \mathrm{min}$ ). If the laboratory estimate of glomerular filtration rate (eGFR) is used, the values (in $\mathrm{mL} / \mathrm{min}$ per $1.73 \mathrm{~m}^{2}$ ) should be adjusted for the patient's body surface area, especially at the extremes of size. ${ }^{14}$

\section{Coagulation tests}

There is increasing recognition that coagulation tests are valuable for informing the management of an acute thrombotic or bleeding event in patients taking NOACs..$^{15}$ In contrast, the role of the tests in guiding dosing in the ambulatory setting remains controversial, partly because of questions about the choice of test and target range.' Routine screening coagulation tests including the INR, activated partial thromboplastin time (aPTT) and thrombin time (TT) - all correlate to varying degrees with plasma concentrations of the NOACs. ${ }^{15}$ However, as the relationships between each of these tests and anticoagulant concentrations varies by drug and by laboratory, interpretation should be performed in consultation with local specialists. Specific advice about interpretation of coagulation tests is available from the Australasian Society of Thrombosis and Haemostasis. ${ }^{13}$

\section{Management of bleeding}

In addition to gauging the severity of bleeding, the patient's recent intake of oral anticoagulants should be evaluated. For example, a clear history of an overdose preceding the bleeding event may inform subsequent decisions for long-term anticoagulation. Laboratory tests may also be needed. Other more definitive tests to identify the bleeding site, such as gastrointestinal endoscopy, are performed as required.

\section{Box Patient monitoring with new oral anticoagulants}

\section{Clinical}

Adherence to therapy

Symptoms and signs of bleeding

Changing comorbidities such as new heart failure

Concomitant medicines

\section{Laboratory}

Renal function

Other tests as clinically indicated e.g. blood counts, liver function tests
For minor bleeding, such as mild epistaxis, local measures may be adequate. For more serious bleeding, such as an intracranial haemorrhage, discontinue the anticoagulant at least until the bleeding has been stabilised and the clinical status of the patient (including ongoing bleeding risk) has been sufficiently evaluated. When bleeding is severe, the patient should be referred to hospital.

While 'antidotes' to apixaban, dabigatran and rivaroxaban exist, ${ }^{16}$ they are parenterally delivered recombinant proteins that are not readily available outside of drug development trials. The exception is idarucizumab, which was recently approved. ${ }^{17}$ Otherwise, the main antidote is time. Drug concentrations and anticoagulant effect are expected to diminish by more than $90 \%$ after treatment has been stopped for four half-lives. The Table lists average half-lives according to anticoagulant and renal and hepatic function. These data may be used to inform the timing of when the anticoagulant should be interrupted before a procedure with a low risk of bleeding. Stopping 2-3 drug half-lives before such procedures has been suggested.13

\section{Are NOACs better than warfarin?}

The purported benefits of the newer oral anticoagulants over warfarin include predictable pharmacokinetics, fewer interactions with foods and other drugs, a lack of a need for routine laboratory coagulation monitoring, and quicker onset and 'offset' of action.

The claim that NOACs have predictable pharmacokinetics is misleading. For example, for a given dosage of dabigatran, the 10th to 90th centiles of observed steady-state concentrations encompassed a five-fold range of values. ${ }^{18}$ This degree of variability is typical for most drugs. ${ }^{19}$ Hence, it is remarkable that clinical outcomes from fixed-dose NOACs have been found to be non-inferior to INR-targeted warfarin. These non-inferiority trial findings are supported by observational studies of real-world use, especially for dabigatran, ${ }^{20,21}$ albeit not entirely. ${ }^{22}$

The lack of an established need for routine coagulation monitoring with NOACs may be convenient for patients who do not have ready access to INR testing for warfarin therapy. However, it makes monitoring adherence and managing thrombotic events more difficult. ${ }^{13}$ Also, although NOACs have fewer food and drug interactions than warfarin, ${ }^{2}$ the relative lack of familiarity with interactions and routine monitoring means that prescribers may miss important interactions.

The quicker onset and 'offset' of action with NOACs is both a positive and a negative. On the one hand, the need for bridging with parenteral anticoagulants may be obviated with NOACs. Conversely, missing even a single dose could result in a period of minimal anticoagulation ${ }^{12}$ (see the Table for half-lives). 
A limitation of both the interventional and observational data so far is the relative lack of Iongitudinal information. The best available evidence is for dabigatran in atrial fibrillation, where the rates of major thrombotic and bleeding events were comparable to warfarin over five years. ${ }^{23}$ Similar data for the other oral anticoagulants, and with 'indefinite' use for venous thromboembolism, are expected.

\section{Conclusion}

Instead of considering whether NOACs are 'superior' to warfarin, it is more constructive to see them as useful arrows in the prescriber's quiver of oral anticoagulants. A patient with adequate renal and hepatic function, not taking other drugs that may interact, and who wishes to minimise blood tests, is a good candidate for apixaban, dabigatran or rivaroxaban. However, if adherence is a potential problem, it may be safer to recommend warfarin. While it is plausible that dose adjustment guided by routine laboratory coagulation monitoring will improve outcomes, the extent of the clinical benefit remains to be seen.' Until then, prescribers should be vigilant in monitoring adherence and renal function to optimise the benefits of NOACs. $\varangle$

\section{Conflict of interest: none declared}

Acknowledgement: We thank Kathryn Henshaw and Eugene Sia for helpful comments in the preparation of this article.

\section{REFERENCES}

1. Chin PK. Which patients may benefit from dose adjustment of non-vitamin $\mathrm{K}$ antagonist oral anticoagulants? Semin Thromb Hemost 2015;41:195-207. http://dx.doi.org/ 10.1055/s-0035-1546465

2. Nutescu E, Chuatrisorn I, Hellenbart E. Drug and dietary interactions of warfarin and novel oral anticoagulants: an update. J Thromb Thrombolysis 2011;31:326-43. http://dx.doi.org/10.1007/s11239-011-0561-1

3. Baber U, Mastoris I, Mehran R. Balancing ischaemia and bleeding risks with novel oral anticoagulants. Nat Rev Cardiol 2014;11:693-703. http://dx.doi.org/10.1038/ nrcardio.2014.170

4. Gonzalez Quesada CJ, Giugliano RP. Selecting an oral anticoagulant for patients with nonvalvular atrial fibrillation. J Thromb Thrombolysis 2015;39:129-38. http://dx.doi.org/ 10.1007/s11239-014-1148-4

5. Tideman PA, Tirimacco R, St John A, Roberts GW. How to manage warfarin therapy. Aust Prescr 2015;38:44-8. http://dx.doi.org/10.18773/austprescr.2015.016

6. Snyder BD, Polasek TM, Doogue MP. Drug interactions: principles and practice. Aust Prescr 2012;35:85-8. http://dx.doi.org/10.18773/austprescr.2012.037

7. Gebler-Hughes ES, Kemp L, Bond MJ. Patients' perspectives regarding long-term warfarin therapy and the potential transition to new oral anticoagulant therapy. Ther Adv Drug Saf 2014;5:220-8. http://dx.doi.org/ $10.1177 / 2042098614552073$

8. Pisters R, Lane DA, Nieuwlaat R, de Vos CB, Crijns HJ, Lip GY. A novel user-friendly score (HAS-BLED) to assess 1-year risk of major bleeding in patients with atrial fibrillation: the Euro Heart Survey. Chest 2010;138:1093-100. http://dx.doi.org/10.1378/chest.10-0134

9. Lip GY, Nieuwlaat R, Pisters R, Lane DA, Crijns HJ. Refining clinical risk stratification for predicting stroke and thromboembolism in atrial fibrillation using a novel risk factorbased approach: the Euro Heart Survey on atrial fibrillation. Chest 2010;137:263-72. http://dx.doi.org/10.1378/chest.09-1584

10. Lip GY, Clemens A, Noack H, Ferreira J, Connolly SJ, Yusuf S Patient outcomes using the European label for dabigatran. A post-hoc analysis from the RE-LY database. Thromb Haemost 2014;111:933-42. http://dx.doi.org/10.1160/TH13-09-0734

11. Shore S, Carey EP, Turakhia MP, Jackevicius CA, Cunningham F, Pilote L, et al. Adherence to dabigatran therapy and longitudinal patient outcomes: insights from the veterans health administration. Am Heart J 2014;167:810-7. http://dx.doi.org/10.1016/j.ahj.2014.03.023

12. January CT, Wann LS, Alpert JS, Calkins H, Cigarroa JE, Cleveland JC Jr, et al.; American College of Cardiology/ American Heart Association Task Force on Practice Guidelines. 2014 AHA/ACC/HRS guideline for the management of patients with atrial fibrillation: a report of the American College of Cardiology/American Heart Association Task Force on Practice Guidelines and the Heart Rhythm Society. J Am Coll Cardiol 2014;64:e1-76. http://dx.doi.org/10.1016/j.jacc.2014.03.022

13. Tran H, Joseph J, Young L, McRae S, Curnow J, Nandurkar H, et al.; Australasian Society of Thrombosis and Haemostasis. New oral anticoagulants: a practical guide on prescription, laboratory testing and peri-procedural/bleeding management. Intern Med J 2014;44:525-36. http://dx.doi.org/10.1111/imj.12448

14. Johnson DW, Jones GR, Mathew TH, Ludlow MJ, Doogue MP Jose MD, et al.; Australasian Creatinine Consensus Working Group. Chronic kidney disease and automatic reporting of estimated glomerular filtration rate: new developments and revised recommendations. Med J Aust 2012;197:224-5. http://dx.doi.org/10.5694/mja11.11329

15. Favaloro EJ, Lippi G. Laboratory testing in the era of direct or non-vitamin K antagonist oral anticoagulants: a practical guide to measuring their activity and avoiding diagnostic errors. Semin Thromb Hemost 2015;41:208-27. http://dx.doi.org/10.1055/s-0035-1546827

16. Crowther M, Crowther MA. Antidotes for novel ora anticoagulants: current status and future potential. Arterioscler Thromb Vasc Biol 2015;35:1736-45. http://dx.doi.org/10.1161/ATVBAHA.114.303402

17. Idarucizumab. Aust Prescr 2016;39:183. http://dx.doi.org/ 10.18773/austprescr.2016.076

18. Reilly PA, Lehr T, Haertter S, Connolly SJ, Yusuf S, Eikelboom JW, et al.; RE-LY Investigators. The effect of dabigatran plasma concentrations and patient characteristics on the frequency of ischemic stroke and major bleeding in atrial fibrillation patients: the RE-LY Trial (Randomized Evaluation of Long-Term Anticoagulation Therapy). J Am Coll Cardiol 2014;63:321-8. http://dx.doi.org/ 10.1016/j.jacc.2013.07.104

19. Duffull SB. Is the ideal anticoagulant a myth? Expert Rev Clin Pharmacol 2012;5:231-6. http://dx.doi.org/ 10.1586/ecp.12.18

20. Graham DJ, Reichman ME, Wernecke M, Zhang R, Southworth MR, Levenson M, et al. Cardiovascular, bleeding, and mortality risks in elderly Medicare patients treated with dabigatran or warfarin for nonvalvular atrial fibrillation. Circulation 2015;131:157-64. http://dx.doi.org/10.1161/ CIRCULATIONAHA.114.012061

21. Abraham NS, Singh S, Alexander GC, Heien H, Haas LR, Crown W, et al. Comparative risk of gastrointestinal bleeding with dabigatran, rivaroxaban, and warfarin: population based cohort study. BMJ 2015;350:h1857. http://dx.doi.org/ 10.1136/bmj.h1857

22. Hernandez I, Baik SH, Piñera A, Zhang Y. Risk of bleeding with dabigatran in atrial fibrillation. JAMA Intern Med 2015;175:18-24. http://dx.doi.org/10.1001/ jamainternmed.2014.5398

23. Connolly SJ, Wallentin L, Ezekowitz MD, Eikelboom J, Oldgren J, Reilly PA, et al. The long-term multicenter observational study of dabigatran treatment in patients with atrial fibrillation (RELY-ABLE) study. Circulation 2013;128:237-43. http://dx.doi.org/10.1161/ CIRCULATIONAHA.112.001139 